\title{
Bernesse periasetabular osteotomi
}

\section{Bernesse periacetabular osteotomy}

\author{
Muharrem İnan ${ }^{1}$, ilker Sarıkaya ${ }^{2}$ \\ ${ }^{1}$ İstanbul Üniversitesi, Cerrahpaşa Tıp Fakültesi, Ortopedi ve Travmatoloji Anabilim Dalı, İstanbul \\ ${ }^{2}$ Çocuk Ortopedi Kliniği, İstanbul
}

\begin{abstract}
Periasetabular osteotomi, adolesan yaş kalça displazilerinin tedavisinde yaygın olarak kullanılan bir tedavi yöntemidir. Ganz tarafından tanımlanan PAO, gerek asetabular kan dolaşımının korunması gerekse stabilitesi nedeniyle, tüm dünyada kabul görmüştür. En önemli dezavantajı, öğrenme eğrisinin uzun olmasıdır. Bu dönemde karşılaşılabilecek komplikasyonlar; sinir yaralanması, osteotominin eklem içine uzaması ve uygun olmayan düzeltmelerdir. Tecrübeli ellerde bu komplikasyonlar en aza indirgenerek, kalça sağ kalımının uzun yıllar sağlanması mümkün olabilmektedir.
\end{abstract}

Anahtar sözcükler: displazi; kalça; osteotomi

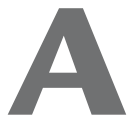

dolesan yaş grubu gelişimsel kalça displazilerinin tedavisinde, periasetabular osteotomiler (PAO) sıklıkla tercih edilmektedir. Eppright, Wagner ve Ninomiya tarafında tanımlanan semisferikal osteotomiler, yaygın kullanılmalarına ve başarılı sonuçlarına rağmen, asetabular parçada dolaşımı bozma ihtimalleri nedeniyle sakıncalı bulunmuştur. ${ }^{[1-3]}$ PAO tekniği, asetabulumun dolaşımı koruyacak şekilde, Ganz tarafından yeniden tanımlanmıştır. ${ }^{[4]}$ Bilimsel sonuçların yayımlanması ile birlikte, tüm dünyada kabul görerek yaygın kullanılmaya başlanmıştır. Steppacher ve arkadaşları tarafından yapılan 20 yıllık kalça sağkalım çalışmalarında, sonuçlar oldukça yüz güldürücüdür. ${ }^{[5]}$ Bu çalışmada, kalça anatomisinin düzeltilmesi, mekanik stabilitenin sağlanması ve kalça içi patolojilerin tedavi edilmesi, başarılı bir sonuç için en önemli etmenler olarak sunulmuştur.

\section{HASTA SEÇiMi}

- Triradiat kıkırdak kapanmış,

- eklem uyumu olan,

- dejeneratif artrit Grade 1-2 ${ }^{[6]}$ ve

- tam çıkık olmayan Tönnis Grade 1-2 kalçalar.
Periacetabular osteotomy is a common method for the treatment of adolesan patients with hip dysplasia. This method described by Ganz is globally well-accepted for preserving blood circulation around acetabulum and improving stability. Long learning curve is the most important disadvantage. Some complications including intra-articular fracture, neurologic injury and insufficient correction might be seen in this long period. Hip joint survival for many years with reduced complication rate is possible by skillful utilization of this method.

Key words: dysplasia; hip; osteotomy

\section{RADYOLOJiK DEĞERLENDIRME}

Radyolojik değerlendirmede, konvansiyonel grafiler halen altın standarttır. Bu amaçla, ayakta çekilen pelvis AP ve false-profile grafiler kullanılmaktadır (Şekil 1a, 1c). ${ }^{[7,8]}$ Ayrıca, eklem uyumunu değerlendirmek için, abduksiyon grafileri çekilir (Şekil 1b). Günümüzde üç boyutlu tomografi ve manyetik rezonans (MR) görüntüleme gibi ileri değerlendirme teknikleri de rutin olarak kullanılmaktadır. ${ }^{[8,9]}$ Böylece, kalça içi patolojilerin daha iyi değerlendirilmesi ve cerrahi planlama yapılırken kalçanın üç boyutlu görüntülenmesi bize avantaj sağlar.

\section{KLINIK DEĞERLENDIRME}

Tedaviyi planlarken, hastanı yürümesi, bacak uzunluk eşitsizlikleri, kas güçleri ve eklem hareket açıklıklarının değerlendirilmesi son derece önemlidir. Ayrıca, patolojileri değerlendirmek için kalça sıkışma testi kullanılmalıdır. Mekanik instabilite değerlendirilmesinde, kalçanın hiperekstansiyona, abduksiyona ve eksternal rotasyona alınması ile hastanın rahatsızlık ve ağı hissetmesi, pozitif gösterge olarak kabul edilir. Kalçanın ekstansiyon

- İletişim adresi: Prof. Dr. Muharrem İnan, İstanbul Üniversitesi, Cerrahpaşa Tıp Fakültesi, Ortopedi ve Travmatoloji Anabilim Dalı, İstanbul Tel: 0212 - 2969450 e-posta: muharreminan@hotmail.com

- Geliş tarihi: 23 Ocak 2015 Kabul tarihi: 23 Ocak 2015 

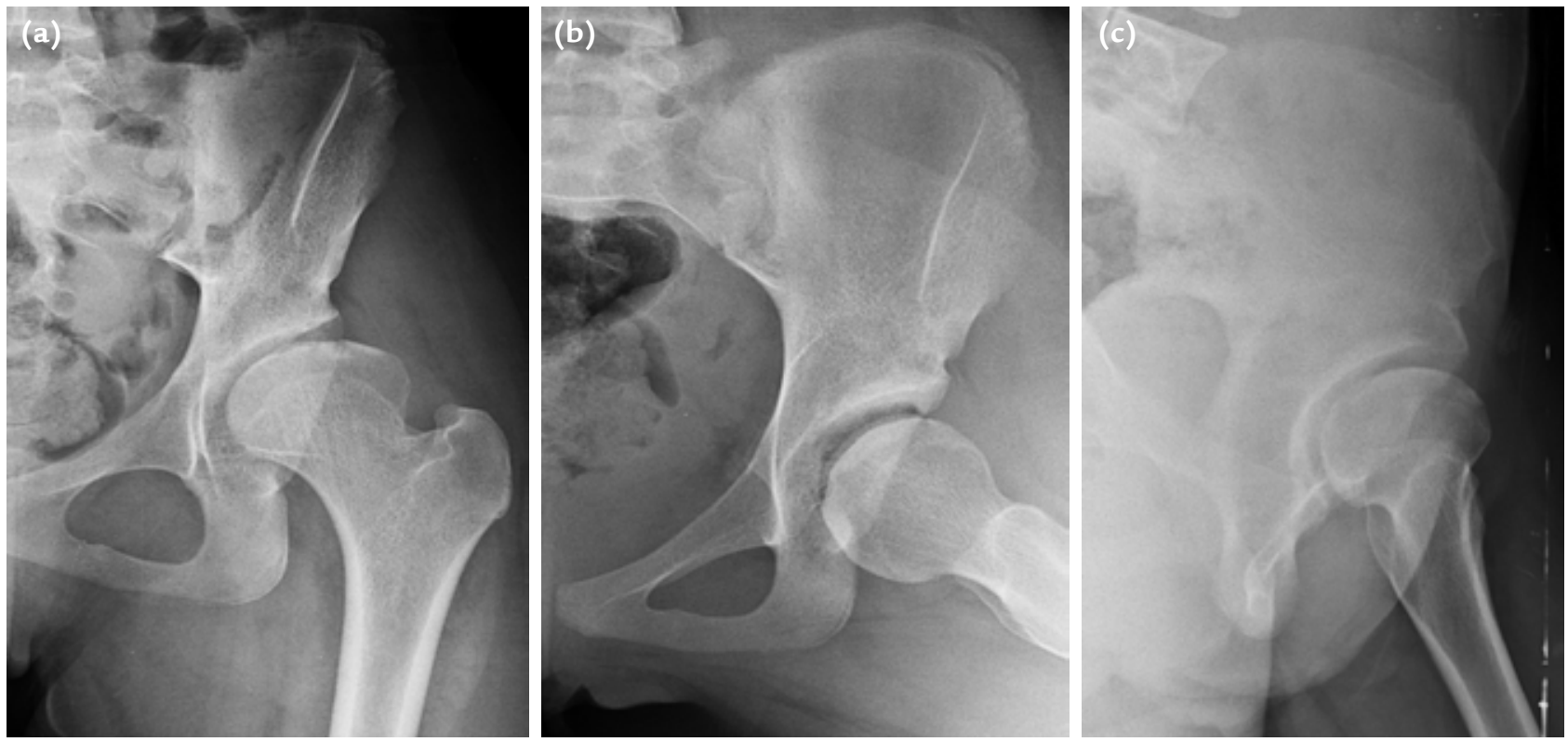

Şekil 1. a-c. Ameliyat öncesi radyorafik değerlendirme için pelvis ön arka, (a) abduksiyon (b) ve false-profile (c) grafiler.

pozisyonunda iken iç ve dış rotasyona alınması ile oluşan ağrı, kalça dejeneratif artritini işaret eder.

\section{CERRAHI TEKNIK}

Sıklıkla kullanılan cerrahi insizyonlar, Modifiye Smith Petersen, ilioinquinal, mini bikini ve minimal invaziv insizyonlardır. İnsizyon cerrahın seçimine göre değişmekle birlikte, osteotomi için tercih edilen sıra; 1) iskial, 2) pübik ve 3 ) iliak osteotomi şeklindedir. Bu amaçla, cilt ve cilt altı geçildikten sonra, sartorius ve tensor fascia lata arasındaki boşluktan lateral femoral kutanöz sinir korunarak girilir. íliak kanat üzerindeki periost keskin olarak ayrılır ve periost altından iliak kanat iç yüzeyi sıyrılır. Abduktor kasların yapışma bölgesi korunmalıdır. Mediyal eklem kapsülü ile iliopsoas kası arasında, Mayo makası kullanılarak bir boşluk yaratılır. Daha sonra, iskial kemik hissedilir ve skopi ile pozisyon kontrol edilir (Şekil 2a).

İskial kemik kesisi için kapsül ile iliopsoas arasında boşluktan eğri ganz osteotomu ilerletilerek anterior iskiumda infrakotiloid oluk hissedilir. Mediyal sirkumfleks arteri korumak için Obturator eksternus kasının proksimalinde kalmak önemlidir. İskial kemiğin lateral ve mediyali dikkatlice hissedilir. Skopi kontrolünde osteotom ucunun inferior asetabular dudağın $1 \mathrm{~cm}$ aşağısına yerleştirildiği kontrol edilmelidir. Öncelikle mediyal korteks 1-2 cm derinlikte kesilir (Şekil 2a). Lateral korteks kesisinde osteotom ucunun korteksten çok ilerletilmemesi siyatik siniri korumak açısından önemlidir.
Pübik kemik kesisi için kalça eklemi fleksiyona alınır. Psoas kası iliopektineal çıkıntı görünecek şekilde mediyale alınarak pübik kemik ortaya konur. Periost altına ekartörler yerleştirilerek obturator arter sinir paketi korunur hale getirilir. Osteotom iliopektineal çıkıntının mediyaline konularak eklem içerisine girmekten kaçınılır (Şekil 2b). Asetabulum hareketini sağlamak için pübik kesinin tam olarak yapılması önemlidir. Labrum tamiri yada kalça içi patolojiler değerlendirilecekse, artrotomi iliak osteotomiden önce yapılmalıdır.

iliak kemik osteotomisine spina iliaka anterior süperiyorun hemen proksimalinden başlanarak siyatik çentik süperiyoru yönünde devam edilir (Şekil 2c). Osteotomi işlemine iliopektineal çizgiye $1 \mathrm{~cm}$ mesafe kalıncaya kadar devam edilir. Bu noktadan 1,5 cm düz osteotom floroskopi kontrol eşliğinde siyatik çentiğin anterior köşesine paralel ve iskial çıkıntıya doğru yönlenir posterior kesi önce iskiumun mediyaline sonrada lateraline doğru yönlendirilir. Eklem içine girme riskine karşı flororskopi ile osteotomun ilerlemesi kontrol edilir (Şekil 2d). Son aşama posteroinferomediyal kesisinin, iskial mediyal ve lateral kesisi ile birleştirilmesidir. Bu iki osteotomiyi birleştirmek için $30^{\circ}$ açılanmış uzun osteotom kullanılır.

Lamina ayırıı iliak kesinin anterior kısmına yerleştirilerek kontrollü kırık ile osteotomi tamamlanır. Bu aşamada spinia iliaka anterior inferiordan osteotomi hattına parelel yerleştirilen bir şanz vidası yardımı ile asetabulum hareket ettirilir. Asetabular yetmezliği gidermek için en sık kullanılan manevra asetabular parçanın laterale, distale ve internal rotasyona alınmasıdır (Şekil 2d). 

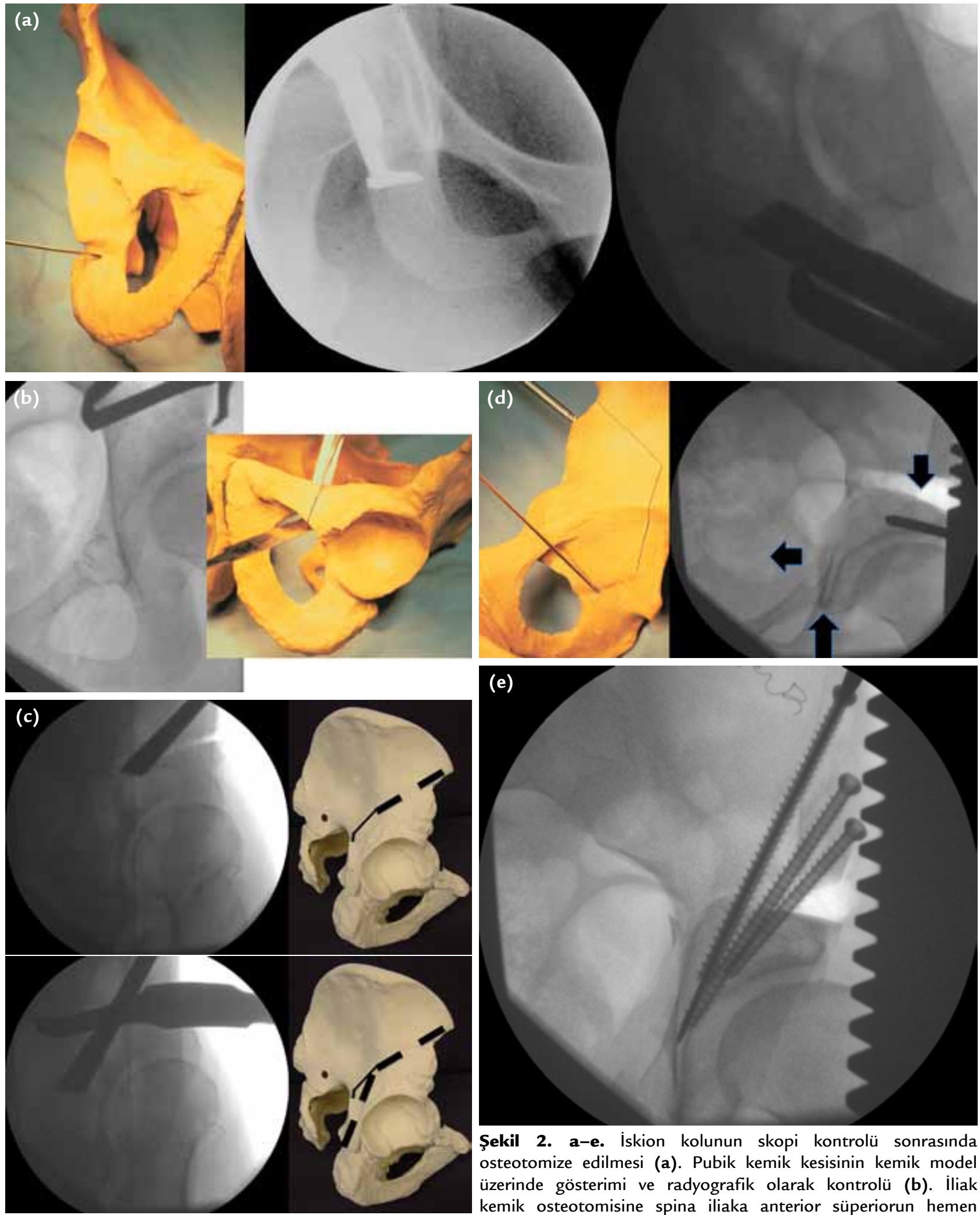

Şekil 2. a-e. İskion kolunun skopi kontrolü sonrasında osteotomize edilmesi (a). Pubik kemik kesisinin kemik model üzerinde gösterimi ve radyografik olarak kontrolü (b). Iliak kemik osteotomisine spina iliaka anterior süperiorun hemen proksimalinden başlanarak, siyatik çentik süperioru yönünde devam edilirken, radyografik ve kemik model üzerinde gösterimi (c). Posterior kesi için osteotom siyatik çentiğin anterior köşesine paralel ve iskial çıkıntıya doğru yönlendirilir. Asetabular yetmezliği gidermek için, asetabular fragman laterale, distale ve internal rotasyona alınmalıdır (d). Tespit amacıyla osteotominin kortikal vidalar ile tespiti (e). 
Radyografide gözyaşı damlası yukarı doğru kalkmış, laterale doğru eğilmiş ve femur başı ile ilişkisinde lateral düzelme miktarı yeterli olmalıdır. Genellikle asetabular parçanın mediyalizasyonu istenilen anterolateral kaplanmanın elde edilmesi için gereklidir.

İstenilen astebuler pozisyon elde edildikten sonra $\mathrm{K}$ telleri ile geçici tespit yapılarak grafi çekilmelidir. Grafi kontrolünde asetabular pozisyon uygun ise (Sourcil horizontal, $\mathrm{CE}$ açısı $20^{\circ}$ ve üzerinde, göz yaşı damlası yükselmiş ve mediyalize ve de Shenton hattının kırılmamış) 3,5 ya da 4,5 mm kortikal vida ile tespit edilir (Şekil 2e). Yumuşak dokular usulüne uygun kapatılarak operasyon sonlandırılır.

Ameliyat sonrasında hemen hasta yük vermeden ayağa kaldırılır. Pasif eklem hareketleri ve kas kuwvetlendirme hastanın ağrıları geçer geçmez başlanır. Radyografi kontrolü sonrasında yaklaşık altı haftada tedrici yüklenmeye ve üçüncü ayda tam yüklenmeye geçilir.

\section{KOMPLIKASYONLAR}

PAO öğrenme eğrisi uzun olan bir cerrahidir ve tecrübeyle birlikte komplikasyonlar azalmaktadır. ${ }^{[10]}$

Komplikasyonlar görülme sıklığına göre;

- nörovasküler yaralanma (siyatik, femoral kutanöz sinir, femoral arter),

- pübik ramusta kaynamama,

- heterotopik ossifikasyon,

- osteotominin eklem içine uzaması ve

- kalça sıkışma sendromu ya da uygun olmayan düzeltme şeklinde sıralanmaktadır.

\section{KAYNAKLAR}

1. Eppright $\mathrm{RH}$. Dial osteotomy of the acetabulum in the treatment of dysplasia of the hip [abstract]. In: Proceedings of the American Orthopaedic Association. J Bone Joint Surg Am 1975;57:1172.

2. Wagner $\mathrm{H}$. Osteotomies for congenital hip dislocation. In: The Hip. Proceedings of the Fourth Open Scientific Meeting of the Hip Society. St. Louis: CV Mosby; 1976. p.45-66.

3. Ninomiya $\mathrm{S}$, Tagawa $\mathrm{H}$. Rotational acetabular osteotomy for the dysplastic hip. J Bone Joint Surg Am 1984;66(3):430-6.

4. Ganz R, Klaue K, Vinh TS, Mast JW. A new periacetabular osteotomy for the treatment of hip dysplasias. Technique and preliminary results. Clin Orthop Relat Res 1988;(232):26-36.

5. Steppacher SD, Tannast M, Ganz R, Siebenrock KA. Mean 20-year followup of Bernese periacetabular osteotomy. Clin Orthop Relat Res 2008;466(7):1633-44. CrossRef

6. Tönnis $\mathrm{D}$. The prearthrotic deformity as origin of coxarthrosis. Radiographic measurements and their value in the prognosis. Z Orthop Ihre Grenzgeb 1978;116(4):444-6.

7. Trousdale R, Ekkernkamp A, Ganz R. Plain radiographs of the adult hip. Sem Arthroplasty 1997;8:10-9.

8. Horii M, Kubo T, Hirasawa Y. Radial MRI of the hip with moderate osteoarthritis. J Bone Joint Surg $\mathrm{Br}$ 2000;82(3):364-8.

9. Cotten A, Boutry N, Demondion X, Paret C, Dewatre F, Liesse A, Chastanet P, Fontaine C. Acetabular labrum: MRI in asymptomatic volunteers. J Comput Assist Tomogr 1998;22(1):1-7.

10. Leunig M, Ganz R. Evolution of technique and indications for the Bernese periacetabular osteotomy. Bull NYU Hosp Jt Dis 2011;69 Suppl 1:S42-6. 